Journal of Fundamental and Applied Sciences

ISSN 1112-9867

Available online at

http://www.jfas.info

\title{
CHEMICAL PROFILES OF HONEYS ORIGINATING FROM DIFFERENT FLORAL SOURCES AND GEOGRAPHIC LOCATIONS EXAMINED BY A COMBINATION OF THREE EXTRACTION AND ANALYSIS TECHNIQUES
}

\author{
D. M. Meloncelli, S. A. M. Windsor*, P. Brooks
}

Inflammation and Healing Cluster, School of Science and Engineering, Faculty of Science, Health, Education and Engineering, University of the Sunshine Coast, Maroochydore DC Queensland 4558 Australia.

Received: 17 November 2014 / Accepted: 02 February 2015 / Published online: 05 February 2015

\begin{abstract}
The chemical profiles of Tasmanian Leatherwood and Manuka honeys from Tasmania and New Zealand have been compared by a combination of GC-MS analysis of volatiles and semi-volatiles, RP-HPLC-DAD analysis of phenolics and flavonoids and HPLC-DAD analysis of derivatised dihydroxyacetone, hydroxymethylfurfural and methylglyoxal. This study found that Tasmanian and New Zealand Manuka honeys have high concentrations of methylglyoxal. However, syringic acid was only detected in Manuka honeys grown in New Zealand. The Tasmanian honeys can be distinguished by the higher concentration of 3phenyllactic acid in Manuka compared to Leatherwood floral sources.
\end{abstract}

Keywords: Leatherwood; Manuka; Leptospermum; GC-MS; HPLC.

\section{INTRODUCTION}

All honeys exhibit antibacterial activity due to their hygroscopic nature, mildly acidic $\mathrm{pH}$ and generation of hydrogen peroxide [1]. In a clinical study of cancer patients with malignant wounds, median wound reduction was $15 \mathrm{~cm}^{2}$ for wounds covered with Activon Medical Manuka (Leptospermum scoparium) Honey impregnated gauze dressings and only $3 \mathrm{~cm}^{2}$ for wounds covered with silver coated primary dressings [2].

Author Correspondence, e-mail: swindsor@usc.edu.au

ICID: 1139049 
Honey has a high sugar concentration including: glucose, fructose, maltose and sucrose [3]. Honey also contains lower concentrations of potentially beneficial compounds [4]. Phenolic compounds in honeys have been linked to numerous biological properties of honeys [5], for example: methyl syringate has been identified as a strong superoxide scavenger, which inhibits the inflammatory cascade [6]; syringic acid is hepatoprotective through suppression of immune-mediate liver inflammation [7]; and 3-phenyllactic acid totally inhibits the growth of Aspergillus fumigatus and Penicillium roqueforti fungi at concentrations $\geq 7.5 \mathrm{mg} / \mathrm{mL}$ [8]. New Zealand Manuka honey is known to exhibit non-peroxide antibacterial activity caused by the active ingredient methylglyoxal (MGO) which arises by chemical conversion from dihydroxyacetone (DHA) during honey maturation [9, 10].

DHA has to-date only been found in Leptospermum nectar [11]. DHA converts to MGO over time and are marker compounds for Leptospermum honey [9]. Honeys can be artificially aged by heat treatment, but this also increases the concentration of potentially harmful compounds present in honey, for example hydroxymethylfurfural (HMF) [12]. The main concern surrounding HMF intake by humans is that sulfotransferase metabolise HMF to its mutagenic derivative sulfomethylfurfural (SMF) by sulfonation of the hydroxyl methyl group [13]. However, differing views persist about the risk HMF and its metabolite SMF pose to human health [14]. For example, genotoxic and mutagenic effects were not observed in in vitro experiments of mammalian cells, except at high ( $\geq 1500 \mathrm{ppm})$ HMF concentrations [15]. Despite the debate over the potential harm HMF poses to humans, the International Honey Commission (IHC) has stated that after processing and/or blending, HMF levels shall not exceed $40 \mathrm{ppm}$, unless the honey originates from regions with tropical ambient temperatures, in which case levels shall not exceed 80 ppm [16].

No study has as yet compared the chemical profiles of New Zealand and Tasmanian Manuka honeys. Another premium Tasmanian honey, Leatherwood (Eucryphia lucida), overlaps both in geographic range and flowering season with Manuka. Potentially, bees and honey processing can mix these floral types. An oxygen radical absorption capacity assay performed on Leatherwood (Eucryphia lucida) honey yielded $7.25 \mu \mathrm{mol}$ Trolox equivalents per gram of honey (TE $\mu \mathrm{mol} / \mathrm{g}$ ) which is classified as high (>5 TE $\mu \mathrm{mol} / \mathrm{g}$ ) antioxidant activity [17]. High quality honeys retail for premium prices, but these honeys are increasingly being counterfeited or substituted with cheaper imitations. Fair legislation requires accurate descriptions on labels, especially food products [18]. Consequently, there is an urgent need to develop robust protocols to chromatographically fingerprint floral sources and geographic origins of honeys. 
Chemical profiles generated by solid-phase extraction and high performance liquid chromatography (HPLC) analysis and liquid-liquid ethyl acetate extraction and gas chromatography mass spectrometry (GC-MS) analysis have previously been used to distinguish between two floral sources in Malaysia. Ferulic and cinnamic acids were detected in Gelam (Melaluca spp.) honeys, but not detected in Coconut (Cocos mucifera) honeys. The concentration of gallic acid was higher in Gelam honeys $(3.3 \pm 0.1 \mathrm{ppm})$ than in Coconut honeys $(0.82 \pm 0.05 \mathrm{ppm})$ and the concentration of benzoic acid was lower in Gelam honeys $(0.80 \pm 0.04 \mathrm{ppm})$ than in Coconut honeys $(1.8 \pm 0.1 \mathrm{ppm})$ [19]. Gallic acid concentration was also a distinguishing feature of Algerian bee pollen from Tlemcen (407 $\pm 2 \mathrm{ppm}$ ) compared to bee pollen from other regions of Algeria (range: $321 \mathrm{ppm}$ to $354 \mathrm{ppm}$ ) as evidenced in the methanolic extracts of pollen analysed via HPLC in a recent study [20].

In 2003, Yao and co-workers [21] observed that the total amount of phenolic compounds was generally lower in Jellybush (Leptospermum polygalifolium) honeys than in Manuka honeys via Amberlite XAD-2 extraction with HPLC analysis. A more recent study has specified these earlier generalisations via head space solid phase microextraction (HS-SPME) and GC-MS analysis: the concentration of 2-methoxyacetophenone is notably lower in Jellybush honeys than in Manuka honeys; and the concentration of cis-linalool oxide and 3,4,5-trimethylphenol are substantially higher in Jellybush honeys than in Manuka honeys [22]. This recent study also determined that lumichrome and p-anisic acid are important distinguishing criteria in the Manuka (not detected) / Kanuka (detected) comparison via solid phase extraction and ultra high performance liquid chromatography - photo diode array - mass spectrometry / mass spectrometry (UHPLC-PDA-MS/MS) [22]. This recent study also identified four compounds unique to Manuka honeys: 2-methylbenzofuran, 2-hydroxyacetophenone, acetyl-2-hydroxy-4(2-methoxyphenyl)-4-oxobutanate and 3-hydroxy-1-(2-methoxyphenyl)-penta-1,4-dione [22]. The variability of syringic acid concentrations in New Zealand Manuka honey have previously been observed by diethyl ether liquid-liquid extraction and GC-MS analysis: $32 \pm$ 23 ppm [23]. This variability has since been assigned to a specific geographic origin of New Zealand Manuka honey. Via solid phase extraction, liquid chromatography and mass spectrometry it was determined that high contents of syringic acid was typical of Manuka honeys originating from the East Coast of New Zealand [24].

This study compared the chromatographic fingerprints of honeys from Leatherwood and Manuka floral sources originating from Tasmania and Manuka honeys originating from Tasmania and New Zealand. For robustness, the protocol involved three different extraction and analysis techniques. Volatile and semi-volatile compounds were obtained from the honey 
matrix by liquid-liquid ethyl acetate extraction and trimethylsilyl (TMS) derivatisation and tentatively identified and semi-quantified by GC-MS analysis. Volatility was imparted to semi-volatile compounds in the ethyl acetate extract by conversion of hydroxyl groups and carboxylic acid groups to TMS ethers and esters, respectively, with the derivatising agent N,O-bis(TMS)trifluoroacetamide (BSTFA) [25]. Repeated ethanol extractions were used to isolate the non-volatile phenolic compounds from the honey matrix and tentative identification was made via reverse phase - high performance liquid chromatography - diode array detection (RP-HPLC-DAD) analysis. DHA, HMF and MGO concentrations were determined by aqueous extraction, $O$-(2, 3, 4, 5, 6-pentafluorobenzyl) hydroxylamine (PFBHA) derivatisation and HPLC analysis.

\section{MATERIALS AND METHODS}

Nine Tasmanian Leatherwood honey samples were provided by Blue Hills Honey, Tasmania, Australia. This company also supplied three Tasmanian Manuka honey samples. A further three Tasmanian Manuka honey samples were provided by Daybreak Apiaries, Tasmania, Australia. Six New Zealand Manuka honey samples were supplied by Comvita, New Zealand. All honeys were produced in the 2012 flowering season and analysed in the University of the Sunshine Coast (USC) laboratories in 2013. All honey samples were stored at $4{ }^{\circ} \mathrm{C}$ at USC until $12 \mathrm{hr}$ prior to analysis, at which time the honey samples were kept at room temperature in a dark cupboard.

HPLC MilliQ grade water was used for analysis in this project. HPLC Chromasolv gradient grade acetonitrile, absolute ethanol, ethyl acetate and acetone were purchased from Merck, Kilsyth, Victoria, Australia. The reagents PFBHA and BSTFA were purchased from SigmaAldrich, Castle Hill, New South Wales, Australia.

The chemical standards that were used for this project were supplied by Comvita, New Zealand and the University of Waikato, New Zealand. The standards that were supplied by Comvita were purchased from Sigma-Aldrich, except for 4-methoxybenzoic acid which was purchased from BDH, Auckland, New Zealand and 4-methoxyphenyllactic acid which was synthesised by Hangzhou Sage Chemical, Hangzhou, China. The standards were reconstituted in acetonitrile at a concentration of $1.5 \mathrm{mg} / \mathrm{mL}$.

Homogenised and subsampled honey ( $2 \mathrm{~g}$ ) was weighed into a $16 \mathrm{~mm}$ x $100 \mathrm{~mm}$ test tube. Ethyl acetate $(2 \mathrm{~mL})$, which contained $\mathrm{n}$-hexadecane internal standard $(107 \mu \mathrm{g} / \mathrm{mL})$, was added to the honey. The test tube was covered with aluminium foil and placed into a $50{ }^{\circ} \mathrm{C}$ water bath for 5 min. The sample was vortexed with a Ratek VM1 Vortex Mixer vigorously 
for $3 \mathrm{~min}$ and returned to the water bath for $5 \mathrm{~min}$. This was repeated a further two times. The sample was settled for $15 \mathrm{~min}$.

The ethyl acetate supernatant was collected with a Pasteur pipette and transferred to a vial and dried with anhydrous $\mathrm{Na}_{2} \mathrm{SO}_{4}(50 \mathrm{mg})$. One ethyl acetate supernatant $(100 \mu \mathrm{L})$ was transferred to a $300 \mu \mathrm{L}$ insert in a new $2 \mathrm{~mL}$ vial for GC-MS analysis. A second $100 \mu \mathrm{L}$ of ethyl acetate supernatant was transferred to a $300 \mu \mathrm{L}$ insert containing 50 L of BSTFA in a 2 $\mathrm{mL}$ vial and heated at $65{ }^{\circ} \mathrm{C}$ for $1 \mathrm{hr}$ prior to GC-MS analysis.

GC-MS analyses were performed on a PerkinElmer Clarus® 580 GS coupled to a PerkinElmer Clarus ${ }^{\circledR}$ SQ 8 S MS. The column was a PerkinElmer Elite-5ms $30 \mathrm{~m} \times 0.25 \mathrm{~mm}$ internal diameter $\times 0.25 \mathrm{~m}$. The carrier gas was constant flow $1.0 \mathrm{~mL} / \mathrm{min}$ He. The injection port was $280{ }^{\circ} \mathrm{C}$ The injection operated at a split ratio $10: 1$, from -1.00 to +1.00 min then opened to 50:1. The oven program operated at $50{ }^{\circ} \mathrm{C}$ for $0.5 \mathrm{~min}$, ramping at $6{ }^{\circ} \mathrm{C} / \mathrm{min}$ until $300{ }^{\circ} \mathrm{C}$. Compound ionisation was at $70 \mathrm{eV}$ electron impact, analysing $\mathrm{m} / \mathrm{z}+50-300$, with a 5 min solvent delay. Peaks were tentatively identified by a combination of their retention index and mass spectrum [26] and semi-quantified relative to an n-hexadecane internal standard (eluting at $20.54 \mathrm{~min}$ in the GC-MS traces) and a response factor of unity was assumed for compound quantitation.

Each chemical standard $(1.5 \mathrm{mg} / \mathrm{mL})$ was analysed by GC-MS with the same method as the samples except that the split ratio was 100:1. Each standard was derivatised with $10 \mathrm{~L}$ of BSTFA and re-analysed by the same GC-MS method as the underivatised standard.

The non-volatile phenolic extracts were obtained by repeated extraction and separation steps. Approximately $100 \mathrm{~g}$ of honey was homogenised in $80 \mathrm{~mL}$ of absolute ethanol at $50{ }^{\circ} \mathrm{C}$. This was cooled slowly to $4{ }^{\circ} \mathrm{C}$ and transferred to $-18{ }^{\circ} \mathrm{C}$ for $2 \mathrm{hr}$. The ethanol supernatant was removed from the sugars. The remaining sugars were re-extracted with $40 \mathrm{~mL}$ of absolute ethanol. The combined ethanol supernatant was rotor evaporated to approximately $15 \mathrm{~g}$ with a Buchi ${ }^{\mathrm{TM}}$ Rotavapour R-205 set to $40{ }^{\circ} \mathrm{C}$ at $100 \mathrm{rpm}$. This semi-concentrate was processed twice more with proportionate volumes of absolute ethanol. When required for analysis, the absolute ethanol was evaporated from the aliquot with nitrogen gas.

The analytical RP-HPLC/DAD analysis of the phenolic extracts were performed on a Perkin Elmer Series 200 Pump and Autosampler with a Flexar® Photo Diode Array detector set for $205 \mathrm{~nm}, 260 \mathrm{~nm}, 290 \mathrm{~nm}$ and $340 \mathrm{~nm}$ wavelength detection. The column was a Synergi Fusion polar embedded Reverse Phase (RP) column (75 mm x 4.6 mm, 4 m particle size). The concentrates $(\sim 2 \mathrm{mg})$ were dissolved in $1.0 \mathrm{~mL}$ of 50:50 MilliQ water: acetonitrile in a 2 
mL HPLC glass vial. Mobile Phase (MP) A was MilliQ water: acetonitrile: formic acid, 89.9:10:0.1, v/v/v and MPB were MilliQ water: acetonitrile: formic acid 10:89.9:0.1, v/v/v. The flow rate was set to $1.2 \mathrm{~mL} / \mathrm{min}$. The gradient program was: $100 \%$ MPA for $2.5 \mathrm{~min}$, graded to $30 \%$ MPA : $70 \%$ MPB over 20.0 min, graded to $10 \%$ MPA : $90 \%$ MPB over 2.0 min, isocratic at 10:90 for $2.0 \mathrm{~min}$, graded back to $100 \%$ MPA over $2.0 \mathrm{~min}$, isocratic at $100 \%$ MPA for $3.0 \mathrm{~min}$. The chemical standards were analysed by the same RP-HPLC/DAD method as phenolic extracts. Peaks were identified by comparison of retention times and Ultra-Violet / Visible spectra with authentic standards.

The methods for the PFBHA derivatised aqueous extraction and HPLC analysis [12, 27] were applied honeys originating from Manuka floral source grown in Tasmania and New Zealand. Statistical analysis was performed on IBM SPSS Version 21. The significance level was set to $\mathrm{P}<0.05$. The Levene's test for equality of variances was performed on group compound concentrations: Tasmanian Leatherwood versus Tasmanian Manuka and Tasmanian Manuka versus New Zealand Manuka. When equality of variances in concentrations could be assumed, independent samples t-tests were used to find differences in mean compound concentrations between groups. When equality of variances in concentrations could not be assumed, MannWhitney $U$ tests were performed to find differences in the distribution of compound concentrations between groups. When differences in the distribution of concentrations were found, independent samples median tests were used to find differences in median compound concentrations. Statistically significant differences between mean (reported as $\mathrm{x} \pm \mathrm{sx}$ ppm) and median (ppm) compound concentrations between groups are reported in the results.

\section{RESULTS AND DISCUSSION}

1. Honeys originating from Leatherwood and Manuka floral sources grown in Tasmania The concentrations of gallic acid and benzoic acid have previously been used to distinguish between honeys originating from Gelam and Coconut floral sources grown in Malaysia which have undergone solid-phase extraction and HPLC analysis and liquid-liquid ethyl acetate extraction and GC-MS analysis [19]. The concentrations of 2'-methoxyacetophenone, cislinalool oxide and 3,4,5-trimethylphenol have previously been used to distinguish between Australian Jellybush and New Zealand Manuka which have undergone HS-SPME and GCMS [22]. Similarly in this study, statistically significant differences are observed in the mean concentrations of 4-methoxybenzoic acid $(\mathrm{P}=0.004)$, 4-hydroxybenzoic acid $(\mathrm{P}<0.001)$ and 4decene-1,10-dioic acid $(\mathrm{P}<0.001)$ between honeys originating from Leatherwood and Manuka floral sources grown in Tasmania which have undergone liquid-liquid ethyl acetate extraction, 
TMS derivatisation and tentative identification and semi-quantification by GC-MS (see Table 1). The concentration of 4-methoxybenzoic acid is higher in Leatherwood honeys ( $5 \pm 2 \mathrm{ppm})$ than in Manuka honeys ( $1 \pm 1 \mathrm{ppm})$ from Tasmania. The concentrations of 4-hydroxybenzoic acid and 4-decene-1,10-dioic acid are lower in Leatherwood honeys $(1 \pm 1 \mathrm{ppm}$ and $1 \pm 2$ ppm, respectively) than in Manuka honeys (5 $\pm 1 \mathrm{ppm}$ and $13 \pm 3 \mathrm{ppm}$, respectively) from Tasmania.

Statistically significant differences are also observed in the median concentrations of benzene acetic acid $(\mathrm{P}=0.021)$, mandelic acid $(\mathrm{P}=0.021)$, 3-phenyllactic acid $(\mathrm{P}=0.021)$, 4hydroxyphenylacetic acid ( $\mathrm{P}=0.001)$, 5-hydroxy-2-hydroxymethyl-4H-pyran-4-one $(\mathrm{P}=0.001)$, 2,3,4-trimethoxymandelic acid $(\mathrm{P}=0.021)$ and oleic acid $(\mathrm{P}=0.021)$ between honeys originating from Leatherwood and Manuka floral sources grown in Tasmania (see Table 1). The median concentrations of benzene acetic acid, mandelic acid, 3-phenyllactic acid, 4hydroxyphenylacetic acid, 5-hydroxy-2-hydroxymethyl-4H-pyran-4-one, 2,3,4trimethoxymandelic acid and oleic acid are lower in Leatherwood honeys (1 ppm, 0.05 ppm, $16 \mathrm{ppm}, 0.03 \mathrm{ppm}, 0.02 \mathrm{ppm}, 0 \mathrm{ppm}$ and $1 \mathrm{ppm}$, respectively) than in Manuka honeys (18 ppm, 10 ppm, 1294 ppm, 3 ppm, 6 ppm, 86 ppm and 8 ppm, respectively) from Tasmania.

In a prior investigation, ferulic and cinnamic acids were detected in Gelam honeys, but not detected in Coconut honeys via solid-phase extraction and HPLC analysis and liquid-liquid ethyl acetate extraction and GC-MS analysis [19]. It has also previously been determined that lumichrome and p-anisic acid are important distinguishing criteria in the Manuka (not detected) / Kanuka (detected) comparison via solid phase extraction and UHPLC-PDAMS/MS [22]. This study determines that lilac aldehyde, 4-(1,1-dimethylpropyl)cyclohexanone, 2-isopropyl-3-hydroxy-but-2-enoic acid, 3,4-dimethoxybenzaldehyde, 2deoxy-3,5-bis-hydroxy, $\gamma$-lactone, 1,4-dimethylindanyl acetate, catechin hydrate and ellagic acid are important distinguishing criteria in the Leatherwood (detected) / Manuka (not detected) comparison. 
Table 1 Detection of compounds in Tasmanian Leatherwood versus Tasmanian Manuka honeys via GC-MS

\begin{tabular}{|c|c|c|c|c|c|c|c|c|c|c|}
\hline \multirow[t]{2}{*}{ Tasmanian honey concentration (ppm) } & \multicolumn{2}{|c|}{ Retention } & \multicolumn{4}{|c|}{ Leatherwood } & \multicolumn{4}{|c|}{ Manuka } \\
\hline & $\begin{array}{l}\text { Time } \\
(\min )\end{array}$ & Index & $\mathrm{x}$ & sx & $\mathrm{n}$ & range & $\mathrm{x}$ & sx & $\mathrm{n}$ & range \\
\hline Benzene acetaldehyde & 7.57 & 1042 & 0 & 0 & 9 & 0 & 2 & 1 & 4 & $1-3$ \\
\hline Lilac aldehyde & 10.33 & 1148 & 0.4 & 0.04 & 9 & $0.3-0.4$ & 0 & 0 & 4 & 0 \\
\hline Benzeneacetic acid TMS ester & 13.90 & 1292 & 2 & 2 & 9 & $1-6$ & 19 & 10 & 4 & $9-29$ \\
\hline 4-(1,1-Dimethylpropyl)-cyclohexanone & 15.35 & 1355 & 0.7 & 0.2 & 9 & $0.4-1$ & 0 & 0 & 4 & 0 \\
\hline $\begin{array}{l}\text { 2-Isopropyl-3-hydroxy-but-2-enoic acid } \\
\text { TMS ether TMS ester }\end{array}$ & 17.23 & 1441 & 2 & 5 & 9 & $0.03-13$ & 0 & 0 & 4 & 0 \\
\hline $\begin{array}{l}\text { Pentonic acid, } \\
\text { 2-deoxy-3,5-bis-O-TMS-, } \gamma \text {-lactone }\end{array}$ & 18.52 & 1498 & 0.5 & 1 & 9 & $0.03-2$ & 0 & 0 & 4 & 0 \\
\hline 4-Methoxybenzoic acid TMS ester & 18.83 & 1513 & 5 & 2 & 9 & $3-9$ & 1 & 1 & 4 & $0-3$ \\
\hline $\begin{array}{l}\text { 3-Phenyllactic acid } \\
\text { TMS ether TMS ester }\end{array}$ & 20.07 & 1579 & 33 & 37 & 9 & $3-112$ & 1174 & 645 & 4 & $337-1769$ \\
\hline $\begin{array}{l}\text { 4-Hydroxybenzoic acid TMS ether TMS } \\
\text { ester }\end{array}$ & 20.96 & 1619 & 1 & 1 & 9 & $0.1-3$ & 5 & 1 & 4 & $3-7$ \\
\hline
\end{tabular}




\begin{tabular}{|l|l|l|l|l|l|l|l|l|l|l|}
\hline $\begin{array}{l}\text { 4-Hydroxyphenylacetic acid TMS ether } \\
\text { TMS ester }\end{array}$ & 21.17 & 1634 & 0.03 & 0.02 & 9 & $0-0.04$ & 3 & 2 & 4 & $2-6$ \\
\hline $\begin{array}{l}\text { 1,4-Dimethylindanyl acetate } \\
\text { 4H-Pyran-4-one, 5-[TMS)oxy]-2- }\end{array}$ & 21.30 & 1643 & 2 & 1 & 9 & $1-3$ & 0 & 0 & 4 & 0 \\
\hline [[TMS)oxy]methyl]- & 1671 & 0.02 & 0.01 & 9 & $0-0.03$ & 6 & 1 & 4 & $4-7$ \\
\hline $\begin{array}{l}\text { 4-Decene-1,10-dioic acid di TMS ester } \\
\text { 2,3,4-Trimethoxymandelic acid TMS } \\
\text { ether TMS ester }\end{array}$ & 26.71 & 1942 & 1 & 2 & 9 & $0.2-5$ & 13 & 3 & 4 & $8-16$ \\
\hline \begin{tabular}{l} 
Oleic acid TMS ester \\
\hline
\end{tabular} & 30.93 & 2208 & 2 & 1 & 9 & $0.5-4$ & 9 & 6 & 4 & $4-15$ \\
\hline
\end{tabular}

The first six of these distinctions were made by liquid-liquid ethyl acetate extraction, TMS derivatisation and tentative identification and semiquantification [lilac aldehyde $(0.4 \pm 0.04 \mathrm{ppm})$; 4-(1,1-dimethylpropyl)-cyclohexanone $(0.7 \pm 0.2 \mathrm{ppm})$; 2-isopropyl-3-hydroxy-but-2-enoic acid $(2 \pm 5 \mathrm{ppm})$; 3,4-dimethoxybenzaldehyde (1 $\pm 0.2 \mathrm{ppm})$; 2-deoxy-3,5-bis-hydroxy, $\gamma$-lactone $(0.5 \pm 1 \mathrm{ppm})$ and 1,4-dimethylindanyl acetate ( $2 \pm 1$ ppm)] by GC-MS (see Table 1) and the last two of these distinctions were made by repeated ethanol extractions and tentative identification via RP-HPLC-DAD analysis (see Table 2). This study also determines that benzene acetaldehyde and 2-methoxybenzoic acid are important distinguishing criteria in the Manuka (detected at $2 \pm 1 \mathrm{ppm}$ and $27 \pm 33 \mathrm{ppm}$, respectively) / Leatherwood (not detected) comparison (see Table 1). 
Small concentrations of DHA $(<200 \mathrm{ppm})$ and MGO $(<20 \mathrm{ppm})$ are observed in honeys deemed to have been originating from the Leatherwood floral source grown in Tasmania (see Table 3). However, DHA has to-date only been found in Leptospermum nectar [11]. This suggests that a low level of honey originating from the Manuka floral type has been mixed with the Leatherwood honeys either during bee foraging or honey processing.

Table 2 Detection of compounds in Tasmanian Leatherwood versus Tasmanian Manuka honeys via HPLC

\begin{tabular}{|l|l|l|l|l|}
\hline $\begin{array}{l}\text { Compound detection (+/-) } \\
\text { in Tasmanian honey }\end{array}$ & $\begin{array}{l}\text { Retention } \\
\text { Time }(\mathrm{min})\end{array}$ & UV/Vis $(\mathrm{nm})$ & $\begin{array}{l}\text { Leatherwood } \\
(\mathrm{n}=4)\end{array}$ & $\begin{array}{l}\text { Manuka } \\
(\mathrm{n}=3)\end{array}$ \\
\hline Kojic acid & 0.95 & $192,216,267$ & + & + \\
\hline Catechin hydrate & 5.58 & $200,230,275$ & + & - \\
\hline 3-Phenyllactic acid & 7.83 & $194,206,255$ & + & + \\
\hline Ellagic acid & 10.25 & $218,250,360$ & + & - \\
\hline Methyl syringate & 11.56 & 209,273 & + & + \\
\hline
\end{tabular}

Table 3 Detection of compounds in Tasmanian Leatherwood versus Tasmanian Manuka honeys via HPLC

\begin{tabular}{|l|c|c|c|c|c|c|c|c|}
\hline \multirow{2}{*}{$\begin{array}{l}\text { Tasmanian } \\
\text { honey }\end{array}$} & \multicolumn{3}{|l|}{ Leatherwood } & \multicolumn{2}{l|}{ Manuka } \\
\cline { 2 - 9 } & $\mathrm{x}$ & $\mathrm{sx}$ & $\mathrm{n}$ & range & $\mathrm{x}$ & $\mathrm{sx}$ & $\mathrm{n}$ & range \\
\hline $\begin{array}{l}\text { DHA } \\
(\mathrm{ppm})\end{array}$ & 63 & 54 & 9 & $28-196$ & 1087 & 1031 & 6 & $23-2329$ \\
\hline $\begin{array}{l}\text { HMF } \\
(\mathrm{ppm})\end{array}$ & 4 & 5 & 9 & $1-16$ & 20 & 25 & 6 & $2-65$ \\
\hline $\begin{array}{l}\text { MGO } \\
(\mathrm{ppm})\end{array}$ & 8 & 5 & 9 & $0-15$ & 114 & 99 & 6 & $23-307$ \\
\hline
\end{tabular}


Honeys originating from Manuka floral source grown in Tasmania and New Zealand In a prior investigation, 2-methoxyacetophenone concentration was found to be notably lower in Australian Jellybush honeys than in New Zealand Manuka honeys [22]. In this study, 2methoxyacetophenone was found in Tasmanian $(6 \pm 7 \mathrm{ppm})$ and New Zealand (10 $\pm 9 \mathrm{ppm})$ Manuka honeys (see Table 4), with no statistically significant differences observed in concentrations between the two geographic locations. Although 2-methylbenzofuran, 2hydroxyacetophenone, acetyl-2-hydroxy-4-(2-methoxyphenyl)-4-oxobutanate and 3-hydroxy1-(2-methoxyphenyl)-penta-1,4-dione have previously been identified as compounds unique to Manuka honeys [22], these four compounds were observed in neither Tasmanian nor New Zealand Manuka honeys in this study.

The concentration of gallic acid has previously been used to distinguish between Algerian bee pollen grown in Tlemcen and other regions of Algeria which have undergone methanolic extraction and HPLC analysis [20]. Statistically significant differences are observed in this study in the median concentrations of succinic acid $(\mathrm{P}=0.048)$ and mandelic acid $(\mathrm{P}=0.048)$ between honeys originating from the Manuka floral sources grown in Tasmania and New Zealand (see Table 4). The median concentration of succinic acid is lower in Tasmania Manuka honeys (7 ppm) than in New Zealand Manuka honeys (18 ppm). The median concentration of mandelic acid is higher in Tasmania Manuka honeys (10 ppm) than in New Zealand Manuka honeys (1 ppm). 
Table 4 Detection of compounds in Manuka honeys from Tasmania versus New Zealand via GC-MS

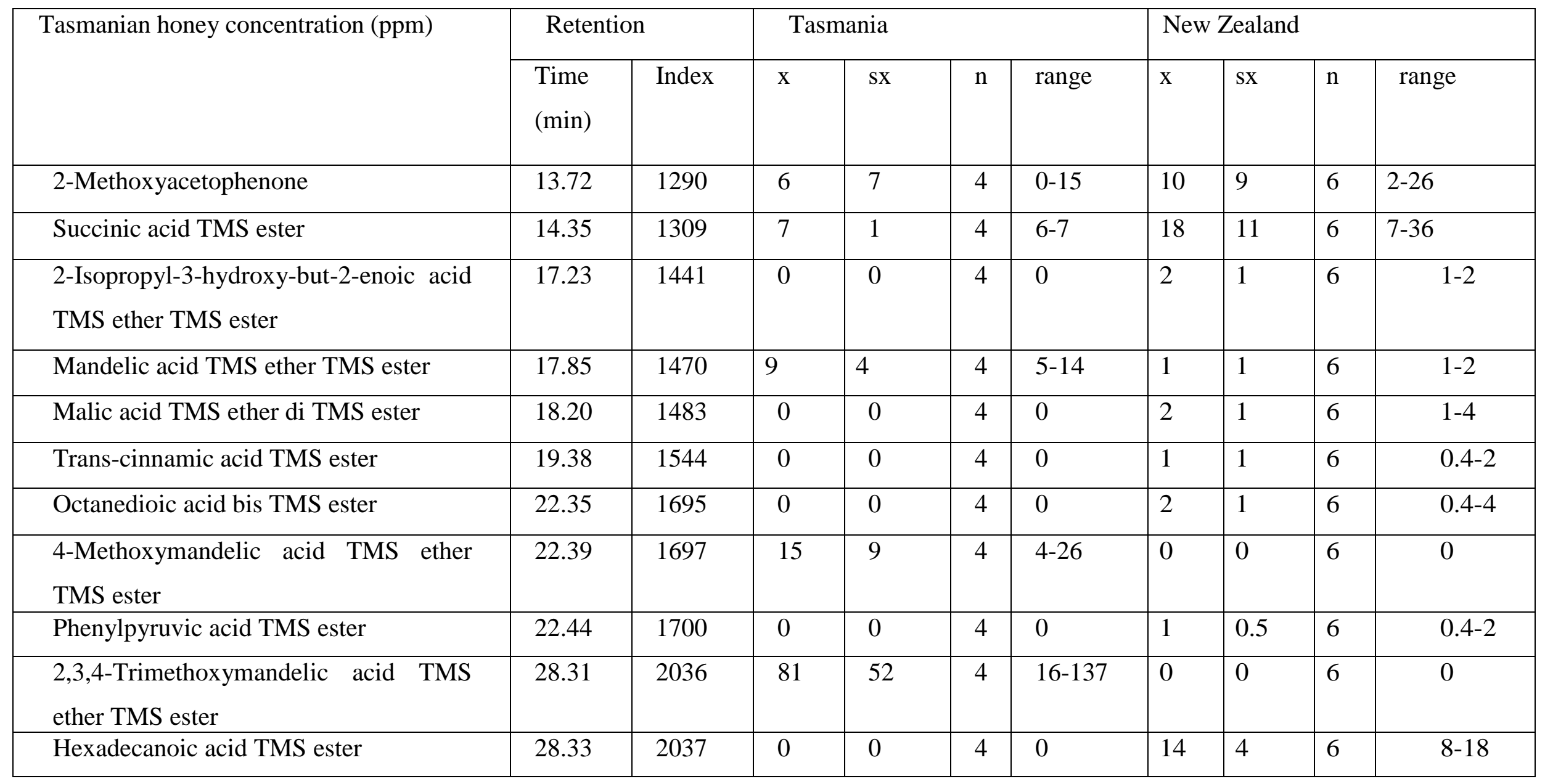


It has previously been determined via solid phase extraction, liquid chromatography and mass spectrometry that high contents of syringic acid was typical of Manuka honeys originating from the East Coast of New Zealand [24]. This current study is consistent with this prior observation, as syringic acid is not detected in Tasmanian Manuka honey which had undergone repeated ethanol extractions and tentative identification via RP-HPLC-DAD analysis (see Table 5). This study also determined that 2-isopropyl-3-hydroxy-but-2-enoic acid, malic acid, trans-cinnamic acid, octanedioic acid, phenylpyruvic acid and hexadecanoic acid are important distinguishing criteria in the New Zealand Manuka (detected) / Tasmanian Manuka (not detected) comparison. These distinctions were made by liquid-liquid ethyl acetate extraction, TMS derivatisation and tentative identification and semi-quantification [2isopropyl-3-hydroxy-but-2-enoic acid ( $2 \pm 1 \mathrm{ppm})$; malic acid ( $\pm 1 \mathrm{ppm})$; trans-cinnamic acid $(1 \pm 1 \mathrm{ppm})$; octanedioic acid $(2 \pm 1 \mathrm{ppm})$; phenylpyruvic acid $(1 \pm 0.5 \mathrm{ppm})$; hexadecanoic acid $(14 \pm 4 \mathrm{ppm})]$ by GC-MS (see Table 4). 4-Methoxymandelic acid and 2,3,4-trimethoxymandelic acid were also identified as important distinguishing criteria in the Tasmanian Manuka (detected at $15 \pm 9 \mathrm{ppm}$ and $81 \pm 52 \mathrm{ppm}$, respectively) / New Zealand Manuka (not detected) comparison (see Table 4).

In this study, no statistically significant differences were observed in DHA, HMF and MGO concentrations between Tasmanian and New Zealand Manuka honeys (see Table 6).

Table 5 Detection of compounds in Manuka honeys from Tasmania versus New Zealand via HPLC

\begin{tabular}{|c|c|c|c|c|}
\hline $\begin{array}{c}\text { Compound detection } \\
(+/-) \text { in Manuka } \\
\text { honey }\end{array}$ & $\begin{array}{c}\text { Retention } \\
\text { Time (min) }\end{array}$ & UV/Vis (nm) & $\begin{array}{c}\text { Tasmania } \\
(\mathrm{n}=3)\end{array}$ & $\begin{array}{c}\text { New Zealand } \\
(\mathrm{n}=6)\end{array}$ \\
\hline Kojic acid & 0.95 & $192,216,267$ & + & + \\
\hline Syringic acid & 6.68 & 208,275 & - & + \\
\hline $\begin{array}{c}\text { 3-Phenyllactic } \\
\text { acid }\end{array}$ & 7.83 & $194,206,255$ & + & + \\
\hline Methyl syringate & 11.56 & 209,273 & + & + \\
\hline
\end{tabular}


Table 6 Detection of compounds in Manuka honeys from Tasmania versus New Zealand via HPLC

\begin{tabular}{|l|l|l|c|c|l|l|l|l|}
\hline \multirow{2}{*}{$\begin{array}{l}\text { Manuka } \\
\text { honey }\end{array}$} & \multicolumn{3}{|c|}{ Tasmania } & \multicolumn{2}{l|}{ New Zealand } \\
\cline { 2 - 9 } & $\mathrm{x}$ & $\mathrm{sx}$ & $\mathrm{n}$ & range & $\mathrm{x}$ & $\mathrm{sx}$ & $\mathrm{n}$ & range \\
\hline $\begin{array}{l}\text { DHA } \\
(\mathrm{ppm})\end{array}$ & 1087 & 1031 & 6 & $23-2329$ & 2154 & 1386 & 6 & $607-4475$ \\
\hline $\begin{array}{l}\text { HMF } \\
(\mathrm{ppm})\end{array}$ & 20 & 25 & 6 & $2-65$ & 8 & 3 & 6 & $4-13$ \\
\hline $\begin{array}{l}\text { MGO } \\
(\mathrm{ppm})\end{array}$ & 114 & 99 & 6 & $23-307$ & 481 & 481 & 6 & $74-1368$ \\
\hline
\end{tabular}

\section{CONCLUSION}

Tasmanian Manuka honeys have a higher concentration of 3-phenyllactic acid than Tasmanian Leatherwood honeys. This perhaps imparts antifungal activity to Tasmanian Manuka honeys [8]. Tasmanian Manuka honeys also have higher concentrations of benzene acetic acid, mandelic acid, 4-hydroxybenzoic acid, 4-hydroxyphenylacetic acid, 5-hydroxy-2hydroxymethyl-4H-pyran-4-one, 4-decene-1,10-dioic acid, 2,3,4-trimethoxymandelic acid and oleic acid than Tasmanian Leatherwood honeys. Manuka honeys can be distinguished from Leatherwood honeys grown in Tasmania by the detection of benzene acetaldehyde and 2-methoxybenzoic acid. Conversely, Leatherwood honeys can be distinguished from Manuka honeys grown in Tasmania by the detection of lilac aldehyde, 4-(1,1-dimethylpropyl)cyclohexanone, 2-isopropyl-3-hydroxy-but-2-enoic acid, 3,4-dimethoxybenzaldehyde, 2deoxy-3,5-bis-hydroxy, $\gamma$-lactone, 1,4-dimethylindanyl acetate, catechin hydrate and ellagic acid. Tasmanian Leatherwood honeys also have a higher concentration of 4-methoxybenzoic acid than Tasmanian Manuka honeys.

Tasmanian and New Zealand Manuka honeys have high concentrations of MGO. This imparts non-peroxide antibacterial activity to Manuka honeys grown in both geographic locations [10]. It has previously been determined that high contents of syringic acid was typical of Manuka honeys originating from the East Coast of New Zealand [24]. The findings in this study are consistent with this prior observation, as syringic acid is not detected in Tasmanian Manuka honey. This perhaps imparts hepatoprotectivity to New Zealand Manuka honeys [7]. Manuka honeys grown in New Zealand can also be distinguished from Manuka honeys grown in 
Tasmania by the detection of 2-isopropyl-3-hydroxy-but-2-enoic acid, malic acid, transcinnamic acid, octanedioic acid, phenylpyruvic acid and hexadecanoic acid. A higher concentration of succinic acid is also indicative of a Manuka honey grown in New Zealand. Conversely, 4-methoxymandelic acid and 2,3,4-trimethoxymandelic acid are detected in Tasmanian Manuka honeys, but not in New Zealand Manuka honeys. Also, the concentration of mandelic acid is higher in Tasmania Manuka honeys than in New Zealand Manuka honeys.

\section{REFERENCES}

[1] Cooper R.A., Jenkins L., Wounds - Compendium Clin. Res. Pract. 2009, 21(2), 29-36.

[2] Lund-Nielsen B., Adamsen L., Gottrup F., Rorth M., Tovler A., Kolmos H.J., Ostomy Wound Manag. 2011, 57(7), 28-36.

[3] Weigel K.U., Opitz T., Henle T., Eur. Food Res. Tech. 2004, 218(2), 147-151.

[4] Pyrzynska K., Biesaga M., Trends Anal. Chem. 2009, 28(7), 893-902.

[5] Estevinho L., Pereira A.P., Moreira L., Dias L.G., Pereira E., Food Chem. Toxicol. 2008, 46(12), 3774-3779.

[6] Stephens J.M., Schlothauer R.C., Morris B.D., Yang D., Fearnley L., Greenwood D.R., Loomes K.M., Food Chem. 2010, 120, 78-86.

[7] Itoh A., Isoda K., Kondoh M., Kawase M., Kobayashi M., Tamesada M., Yagi K.,, Biol. Pharm. Bull. 2009, 32(7), 1215-1219.

[8] Strom K., Sjogren J., Broberg A., Schnurer J., Appl. Environ. Microbiol. 2002, 68(9), 4322-4327.

[9] Adams C.J., Manley-Harris M., Molan P.C., Carbohydr. Res. 2009, 344, 1050-1053.

[10] Adams C.J., Boult C.H., Deadman B.J., Farr J.M., Grainger M.N.C., Manley-Harris M., Snow M.J., Carbohydr. Res. 2009, 344, 2609.

[11] Williams S., King J., Revell M., Manley-Harris M., Balks M., Janusch F., Kiefer M., Clearwater M., Brooks P., Dawson M., J. Agric. Food Chem 2014, 62, 10332-10340.

[12] Windsor S., Kavazos K., Brooks P.R., J. Pharmacogn. Phytother. 2013, 5(1), 21-25.

[13] Teixido, E., Nunez O., Santos F.J., Galceran M.T., Food Chem. 2011, 126, 1902-1908.

[14] Spano N., Ciulu M., Floris I., Panzanelli A., Pilo M.I., Piu P.C., Salis S., Sanna G., Talanta 2009, 78, 310-314.

[15] Janzowski C., Glaab V., Samimi E., Schlatter J., Eisenbrand G., Food Chem. Toxicol. 2000, 38, 801-809.

[16] Ajlouni S., Sujirapinyokul P., Food Chem. 2010, 119, 1000-1005. 
[17] Dragar C., Antioxidant capacity of some Tasmanian Honeys. New Town, Tasmania, Australia, 2009.

[18] Molan P.C., Bee World 1998, 79(2), 59-68.

[19] Aljadi A.M., Yusoff K.M., Turkish J. Med. Sci. 2003, 33, 229-236.

[20] Rebiai A., Lanez T., Belfar M.L., PhytoChem BioSub J. 2014, 8(3), 190-197.

[21] Yao L., Datta N., Tomas-Barberan F.A., Ferreres F., Martos I., Singanusong R., Food Chem. 2003, 81, 159-168.

[22] Beitlich N., Koelling-Speer I., Oelschlaegel S., Speer K., J. Agric. Food Chem. 2014, $62,6435-6444$.

[23] Wilkins A.L., Lu Y., Molan P.C., J. Apic. Res. 1993, 32(1), 3-9.

[24] Oelschlaegel S., Gruner M., Wang P.N., Boettcher A., Koelling-Speer I., Speer K., J. Agric. Food Chem. 2012, 60(29), 7229-7237.

[25] Creaser C.S., Koupai-Abyazani M.R., Stephenson G.R., Org. Mass Spectrom. 1991, $26,157-160$.

[26] Adams R.P., Identification of essential oil components by gas chromatography/mass spectroscopy. 4th ed. Carol Stream: Allured Pub. Cor. 2007.

[27] Windsor S., Pappalardo M., Brooks P.R., Williams S., Manley-Harris M., J. Pharmacogn. Phytother. 2012, 4(1), 6-11.

\section{How to cite this article}

Meloncelli, D. M, Windsor S. A. M, Brooks P. Chemical profiles of honeys originating from different floral sources and geographic locations examined by a combination of three extraction and analysis techniques. J Fundam Appl Sci. 2015, 7(2), 169-184. 